\title{
О СОЦИАЛИЗАЦИИ И ГЕНЕТИЧЕСКОЙ ИЗМЕНЧИВОСТИ ПРИ ДОМЕСТИКАЦИИ (на примере пород собак)
}

\author{
В.И. ГЛАЗКО1, 2 , Г.Ю. КОСОВСКИЙ 2 , Т.В. БЛОХИНА1, А.А. ЖИРКОВАํㅛ, \\ Т.Т. ГЛАЗКО1, 2
}

\begin{abstract}
Социальная активность является основой взаимодействия между разными видами в процессе формирования общей ниши, в том числе при доместикации животных. Среди характеристик «доместикационного синдрома» универсальной для разных видов признается повышенная социальная активность (M.A. Zeder, 2017). Предполагается, что некоторые элементы такого повышения обусловлены определенной неотенизацией ряда метаболических путей головного мозга (M. Somel с соавт., 2009). Это хорошо согласуется с данными о связи «доместикационного синдрома» с замедлением клеточной пролиферации нервного гребня (M.A. Zeder, 2015). У человека описан синдром гиперсоциализации (синдром Вильямса-Берена - WBS), связанный с гемиделецией/гемидупликацией области 7q11.23, включающей 25-28 генов, продукты которых критичны для разных функций центральной нервной системы (А. Antonell с соавт., 2010). Обнаружено, что комплекс таких генов находится на хромосоме 6 у псовых, а домашняя собака, рассматриваемая в последние годы как основной модельный объект для изучения генетических механизмов доместикации (E.A. Ostrander с соавт., 2019), отличается от волков присутствием в этой области инсерций транспозонов, повышенного метилирования и пониженной экспрессией генов в этом участке (B.M. von Holdt c coaT., 2017, 2018; D. Tandon c coaвт., 2019 ). Целью настоящей работы был анализ таких инсерций в области ключевого гена WBSCR17 (6-я хромосома Canis familiaris), ассоциированного с повышенной социальной активностью собак (районы интронов Сfa6.6 и Сfa6.7), у представителей разных пород и межвидовых гибридов с шакалами, а также выяснение присутствия мобильных генетических элементов в этих районах. В результате показано наличие в них последовательностей с высокой гомологией к неавтономному диспергированному ядерному элементу SINEC2A1_CF (94\% гомологии) и к двум участкам эндогенного ретровируса 3 , последовательности которого описаны у человека и крупного рогатого скота (около 80 \% гомологии). Таким образом, показано увеличение изменчивости по наличию и числу инсерций в районы Cfa6.6 и Cfa6.7 у собак разных пород и гибридов, присутствие в них участков гомологии к эндогенным ретровирусам человека и крупного рогатого скота, а также короткого диспергированного ядерного элемента, видоспецифичного для домашней собаки, - SINEC2A1_CF, несущего гексануклеотид AATAAA, который способствует завершению транскрипции. Полученные данные позволяют предполагать вовлечение ретровирусов при формировании общей ниши в процессе доместикации, что приводит к повышенной изменчивости, способствующей отбору животных с гиперсоциализацией.
\end{abstract}

Ключевые слова: доместикация, гиперсоциализация, синдром Уильямса-Берена, ретротранспозоны, породы и гибриды собак, общая ниша.

Процесс одомашнивания в основном рассматривается по отношению к человеку, к искусственному отбору, как выделение объекта доместикации из дикой природы с полным контролем его жизненного цикла человеком. В то же время доместикация - пример мутуализма, который наблюдается не только между человеком и домашними видами растений и животных. Этот тип взаимоотношений эволюционно гораздо старше и весьма широко распространен в природе, особенно среди социализированных видов, например у муравьев-листорезов. Еще один яркий пример - мутуализм грибов и растений, водорослей, бактерий. Мутуалистические взаимодействия формируются в ходе коэволюционного процесса отбора носителей мутаций и сопутствующих поведенческих, физиологических, морфологических изменений у обоих партнеров при формирования общей экологической ниши $(1,2)$.

Ключевым условием для доместикации животных служит предрасположенность к социализации, включающая пониженную агрессивность, социальную толерантность, исследовательские тенденции. Имеются данные о том, что социокультурные особенности ниш, созданных человеком, вносят относительно больший вклад во внутривидовую дифференциацию 
культурных растений и доместицированных животных, чем экологические факторы (3). Интересно отметить, что предполагаемый предковый вид человека - бонобо (Pan paniscus), существенно отличается от шимпанзе своей толерантностью - способностью делиться пищей с представителями других видов (4).

В условиях экологических изменений и сужения биоразнообразия доместицированных животных, обусловленного разными причинами, выяснение механизмов доместикации становится важной проблемой для управления генетическими ресурсами сельскохозяйственных видов (5).

Наиболее древний вид среди доместицированных животных - собака (Canis lupus familiaris), одомашнивание которой связано с цивилизацией охотников-собирателей, предшествующей аграрной цивилизации. Принято считать, что самое длительное время коэволюции человека и собаки в общей нише может позволить выявить ключевые геномные мишени доместикации. В этой связи в последние годы домашняя собака стала ведущей моделью исследований по выявлению генов и генных комплексов, связанных с доместикацией $(6,7)$.

У человека описан синдром Вильямса-Берена (Williams-Beuren syndrome - WBS, синдром гиперсоциальности), вызванный соответственно гемиделецией или гемидупликацией 28 генов в области 7q11.23 (8). WBS представляет собой аутосомно-доминантное расстройство, вызванное геномными перестройками из-за больших регионоспецифичных изменений, присутствием Alu транспозонов (неавтономных коротких диспергированных ядерных элементов), которые могут приводить к неаллельной гомологичной рекомбинации в мейозе (9-11). Частота встречаемости WBS в популяции составляет около $1 / 10000$ для WBS гемизиготности и $1 / 20000$ для WBS гемодупликаций. Делеция/дупликация WBSCR (Williams-Beuren syndrome critical region) приводит к гемизиготности/гемодупликации 25-28 генов, объясняющей наблюдаемые фенотипические проявления (12). Среди прочих, участок WBSCR содержит гены, кодирующие факторы регуляции транскрипции, например GTF2I, GTF2IRD1, BAZ1B, MLXIPL, а также сигнальные молекулы FZD9, TBL2, LIMK1 (13). Предполагается, что дозировка GTF2I может изменить баланс возбуждения/торможения (14), что согласуется с многочисленными доказательствами, свидетельствующими о дисбалансе соотношения между возбуждением и торможением в кортикальных нейронах как основном субстрате для развития сети общительности $(15,16)$.

Блок генов, соответствующий области 7q11.23 человека, обнаружен на 6-й хромосоме домашней собаки (CFA6). Сравнительные исследования, посвященные механизмам, обусловливающим повышенную склонность собак к инициированию социальных контактов по сравнению с социализированными людьми серыми волками, объясняли это поведение как тип поведенческой неотении, сохранение ювенильных черт (17), что само по себе потенциально является результатом транскрипционной неотении в мозге (18). Обнаружено, что структурные варианты генов WBS, например в случае GTF2I и его паралогов, лежат в основе стереотипной гиперсоциальности у домашних собак и лис $(17,19)$.

Известно, что транскрипты WBSCR17 преимущественно экспрессируются в мозжечке, гиппокампе, таламусе и коре головного мозга крыс (20), причем исследования подтверждают влияние WBSCR17 на морфологию клеток и трафик через клеточные мембраны (21). WBSCR17 (у человека GALNT17 - N-ацетилгалактозаминилтрансфераза) с высокой активностью экспрессируется в коре головного мозга, участвует в функции лизосом, клеточной адгезии и формировании внеклеточного матрикса (22). 
Выявление у собак генетических основ повышенной предрасположенности к социальной активности и обучаемости имеет особое значение при подборе собак-помощников. Например, при подготовке собак-поводырей для слепых более $60 \%$ особей признаются непригодными в основном изза проблем поведения (23). Обнаружено, что четыре инсерции ретротранспозонов (TE) в генах WBSCR17 (Cfa6.6 и Cfa6.7), GTF2I (Cfa6.66) и POM121 (Cfa6.83) ассоциированы с изменчивостью по тестам Canine Behavioral Assessment and Research Questionnaire (C-BARQ, http://www.cbarq.org). Одна из таких инсерций в WBSCR17 оказалась наиболее тесно связана с повышенной предрасположенностью к общению с человеком. Выявленные ТЕ локализуются в интронах генов WBSCR17 и GTF2I, а также в межгенном пространстве, однако оказываются ассоциированы с повышенным метилированием комплекса генов этого хромосомного участка, с их пониженной экспрессией и изменчивостью по числу копий ТЕ $(24,25)$.

К настоящему времени накоплены данные, свидетельствующие о существенных различиях в распределении ТЕ у таких видов, как домашняя собака (Canis lupus familiaris), серый волк (Canis lupus) и красный волк (Cuon alpinus), которые связывают с процессами одомашнивания (26). Так, на долю ТЕ приходится 41,75 \% нуклеотидных последовательностей генома собаки, что выше, чем у серого волка $(39,26 \%)$ и у красного волка $(38,51 \%)$. Наиболее различающимися компонентами ТЕ в этих геномах являются длинные диспергированные ядерные элементы LINE1 (L1) и микросателлиты, на 86,1 \% отличающие собаку от серого волка и на 83,2 \% - собаку от красного волка. Содержание специфичных для псовых L1 Canis1 и L1 Cf в геноме собаки значительно выше и, в частности, почти вдвое выше, чем в геномах серого и красного волков. Предполагается, что подсемейства L1 Canis1 и L1 Cf могли быть накоплены в геноме собаки в процессе одомашнивания. Неавтономный короткий диспергированный ядерный элемент SINEC Cf в геноме собаки встречается 27,3 млн раз, что в 1,16 раза больше, чем в геноме серого волка, и в 1,23 раза больше, чем в геноме красного волка. Можно ожидать, что представленность ТЕ вносит свой вклад и в различия профилей метилирования геномов у собак и волков, а также в межпородные особенности собак (27).

У ряда пород собак ранее были выявлены инсерции ретротранспозона (без исследований его происхождения и гомологий с другими транспозонами) в участке 6-й хромосомы размером 5 Мб (у человека делеции в этом участке связаны с проявлением синдрома WBS), приводящие к образованию вариантов длин генов, ассоциированные с поведенческими реакциями (17). Однако следует отметить, что генетические основы поведенческих характеристик и молекулярные механизмы структурных изменений генов, связанных с одомашниванием, еще очень мало изучены и требуют системных исследований.

В настоящей работе, как и в исследованиях В.M. von Holdt с соавт. (17), мы обнаружили изменчивость по наличию и числу инсерций в районы Cfa6.6 и Cfa6.7 с использованием праймеров, представленных в работе (17), фланкирующих последовательности интрона гена WBSCR17 - ключевого в определении повышенной социальной активности собак, у представителей разных пород и гибридов с шакалом. Полученные ПЦР-продукты соответствовали ожидаемой величине фрагментов в случае наличия или отсутствия инсерции (соответственно 555 и 357 п.н. для Cfa6.6, 504 и 269 п.н. для Cfa6.7). С применением методов биоинформатики нами выделен соответствующий участок в референтном геноме лабрадора ретривера и оценено присутствие в нем участков гомологии к ретротранспозонам. 
Целью работы было определение наличия или отсутствия инсерций в районе локуса WBSCR17 у представителей нескольких групп собак вьетнамские аборигенные, специализированные охотничьи ловчие борзые и потомство межвидового гибрида собаки и шакала (породная группа шалайки) при помощи двух пар праймеров к районам Cfa6.6 и Cfa6.7, а также анализ нуклеотидных последовательностей участков Cfa6.6 и Cfa6.7 локуса WBSCR17 в референтном геноме лабрадора ретривера на присутствие в них ретротранспозонов различного происхождения.

Методика. Для сравнения использовали генетический материал от 9 особей различных пород борзых, 9 собак вьетнамских пород и 5 шалаек. Образцы крови и тканей собак и шалаек предоставлены кафедрой зоологии ФГБОУ ВО РГАУ-МСХА им. К.А. Тимирязева. Экстрагирование ДНК проводили с помощью наборов Экстран-1, Экстран-2 (ООО «Синтол», Россия), следуя инструкции от производителя.

В качестве праймеров были взяты следующие последовательности: для Cfa6.6 - forward 5'-CCCCTTCAGCCAGCATATAA-3', reverse 3'- TTCTCTGGGCTGTCTGGACT-5', для Cfa6.7 - forward: 5'- TGGAGCCATGATTAGGAAGG-3', reverse 5'- TAAGGAAGGACCCCATTTCC-3' $(17,23)$. Полимеразную цепную реакцию (ПЦР) проводили на амплификаторе Терцик (ООО «ДНК-технология», Россия) с применением смеси ПЦР (ООО «Синтол», Россия) согласно рекомендациям производителя. Условия и стадии ПЦР: первоначальная денатурация 2 мин при $94{ }^{\circ} \mathrm{C} ; 40$ циклов - денатурация 30 с при $94{ }^{\circ} \mathrm{C}$, отжиг 30 с при $58{ }^{\circ} \mathrm{C}$, элонгация 2 мин при $72{ }^{\circ} \mathrm{C}$; заключительная элонгация 10 мин при $72{ }^{\circ} \mathrm{C}$. Фрагменты разделяли методом горизонтального электрофореза в 1,5\% агарозном геле с окрашиванием бромистым этидием. В качестве маркера молекулярных масс для определения длин полученных фрагментов использовался ДНК-маркер 100 bp +1.5 $\mathrm{Kb}+3$ Kb (12 фрагментов от 100 до 3000 п.н.) (НПО «СибЭнзим», Россия). Нуклеотидные последовательности фрагментов гена WBSCR17 с инсерциями (555 п.н. для Cfa6.6 и 504 п.н. для Cfa6.7) были выделены с использованием программы BLASTn (BLAST: Basic Local Alignment Search Tool, https://blast.ncbi.nlm.nih.gov/Blast.cgi) в референтном геноме лабрадора ретривера (ROS_Cfam_1.0 Genome Assembly, https://www.ncbi.nlm.nih.gov/assembly/GCF_014441545.1/, а также UNSW_CanFamBas_1.0 Genome Assembly, https://www.ncbi.nlm.nih.gov/assembly/GCA_013276365.1) на 6-й хромосоме в процессе поиска участков гомологии к фланкирующим праймерам районов Cfa6.6 и Cfa6.7 с целью определения присутствия в нем участков, гомологичных ТЕ разного происхождения. Поиск участков выполняли с помощью программы Giri Repbase (https://www.girinst.org/repbase/) и программного обеспечения CENSOR (http://www.girinst.org/censor/index.php) (28).

Результаты. При анализе результатов электрофоретического разделения продуктов амплификации участков геномной ДНК, фланкированных парой праймеров к Cfa6.6, получены следующие данные. У вьетнамских собак и шалаек были обнаружены фрагменты размером 555-575 и 350-375 п.н. (рис. 1), а также более длинные фрагменты размером до 850-875 п.н., которые чаще встречались у представителей борзых собак.

Спектр продуктов амплификации, полученный у исследованных животных с использованием пары праймеров к участку Сfa6.7, содержал как фрагменты ожидаемых величин 500-525 п.н. (с инсерциями) и 280-300 п.н. (без инсерций), так и более длинные последовательности, размер которых составлял от 600 до 800 п.н. (рис. 2). 

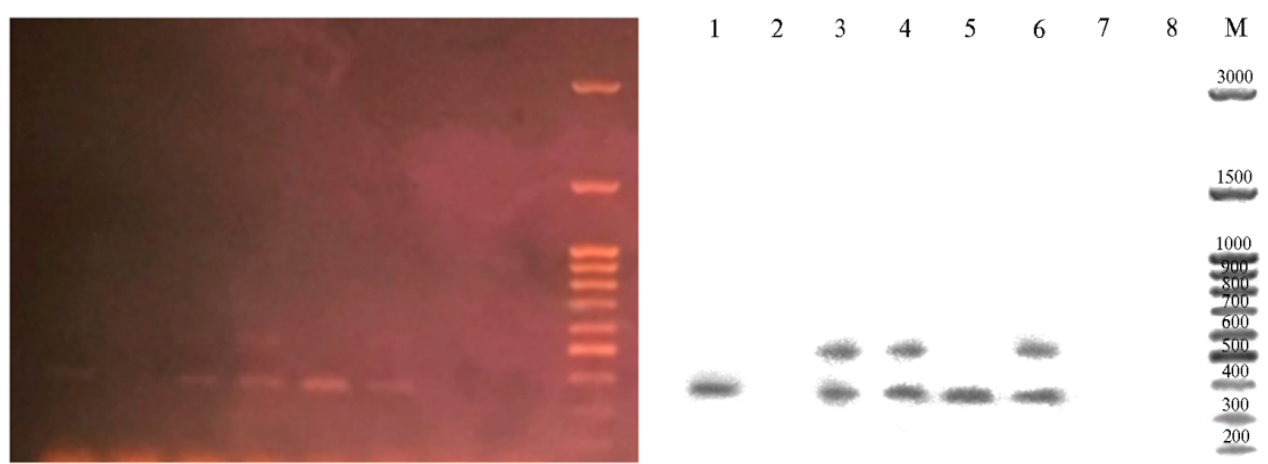

Рис. 1. Электрофоретический спектр продуктов ПЦР-амплификации участков геномной ДНК, фланкированных праймерами к геномным участкам Cfa6.6, у собак: 1 - вьетнамский фукуок, 2 - вьетнамская волкообразная собака, 3 - вьетнамский хмонг, 4-6 - шалайки; М - маркер молекулярных масс $100 \mathrm{bp}+1.5 \mathrm{~Kb}+3 \mathrm{~Kb}$ (НПО «СибЭнзим», Россия). Фрагменты длиной 350-375 и 550-575 п.н.
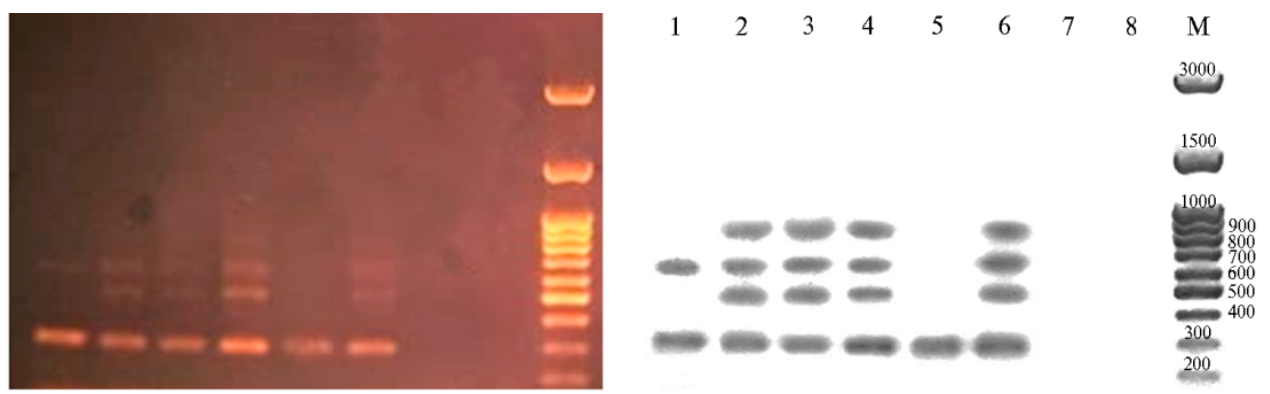

Рис. 2. Электрофоретический спектр продуктов ПЦР-амплификации участков геномной ДНК, фланкированных праймерами к геномным участкам Cfa6.7, у собак: 1 - вьетнамский фукуок, 2 - вьетнамская волкообразная собака, 3 - вьетнамский хмонг, 4-6 - шалайки; М - маркер молекулярных масс $100 \mathrm{bp}+1.5 \mathrm{~Kb}+3 \mathrm{~Kb}$ (НПО «СибЭнзим», Россия). Фрагменты длиной 290-300, 500-510, 650-670 и 850-870 п.н.

На основании полученных данных можно заключить, что в ДНК собак, история одомашнивания которых крайне различна по времени и степени влияния искусственного отбора, наблюдается выраженный полиморфизм исследованных районов по длинам геномных фрагментов, фланкированных праймерами к участкам Cfa6.6 и Cfa6.7. Среди них присутствуют как спрогнозированные участки с инсерциями фрагментов ретротранспозонов (длиной соответственно 555 и 504 п.н.) и без инсерций (фрагменты длиной 357 и 269 п.н.), так и в некоторых случаях более длинные участки, наличие и величина которых, по нашему предположению, может свидетельствовать о появлении уникальных инсерций и дупликаций внутри исследуемой области. Полученные данные согласуются с результатами генотипирования этих участков в геномах представителей разных пород собак, о чем сообщали и другие исследователи (23).

Как отмечалось выше, инсерции ТЕ в локус WBSCR17 на участках Cfa6.6 и Cfa6.7 6-й хромосомы домашней собаки существенно влияют на повышение метилирования и снижение экспрессии ряда генов в этой области (23). Для того чтобы выяснить, присутствие каких именно ТЕ типично для этого района, мы сравнили последовательности фрагмента 555 п.н., полученного с праймерами к Cfa6.6, и фрагмента 504 п.н., фланкированного праймерами к Cfa6.7, в секвенированных последовательностях генома домашней собаки (ROS_Cfam_1.0 Genome Assembly, https://www.ncbi.nlm.nih.gov/assembly/GCF_014441545.1/ и UNSW_CanFamBas_1.0 Genome Assembly, https://www.n̄obi.nlm.nih.gov/assembly/GCA_013276365.1). В результате выявили нуклеотидные последовательности, представленные на рисунках 3 и 4. 


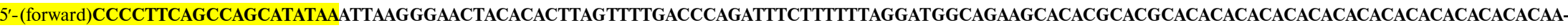

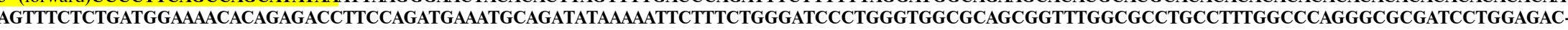

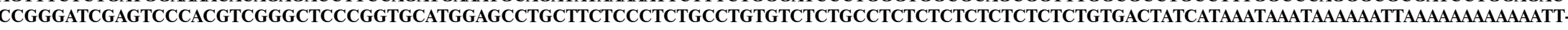

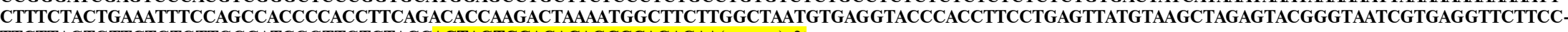
TTCTTAGTGTTCTGTGTTGGCATCGGTTGTCTACCACTAGTCCAGACAGCCCAGAGAA(reverse)-3

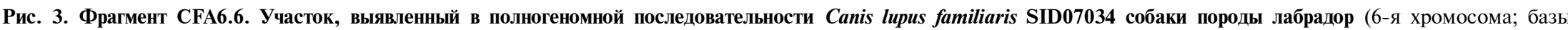

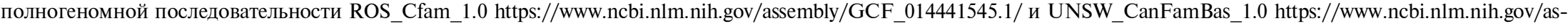
sembly/GCA_013276365.1), фланкированный праймерами к району CFA6.6. Участки гомологий к праймерам выделены желтым цветом.

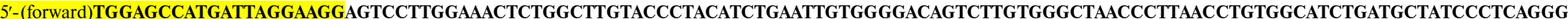

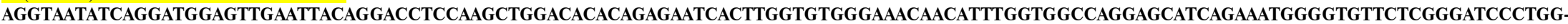

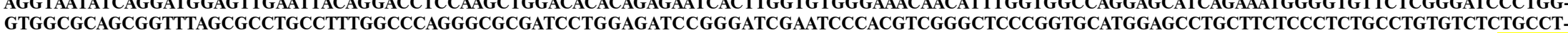

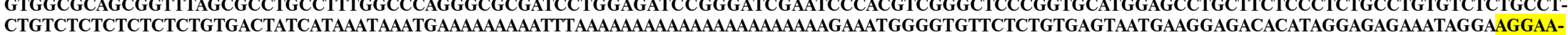
ATGGGGTCCTTCCTT(reverse)-3'

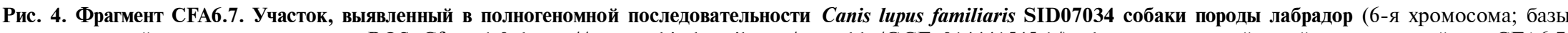

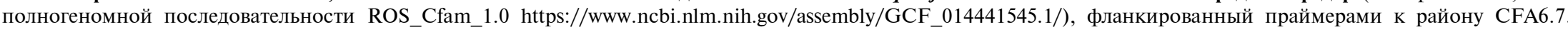
Участки гомологии к праймерам выделены желтым цветом. 


\section{$1 \oplus 0 \ominus$ r}

Б

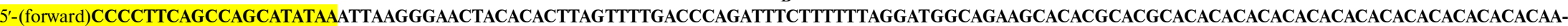

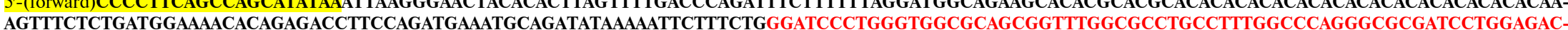

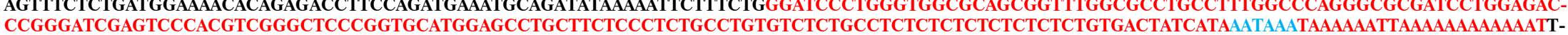

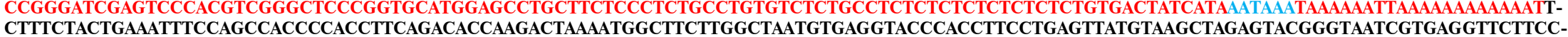
CTTTCTACTGAAATTTCCAGCCACCCCACCTTCAGACACCAAGACTAAAATGGCTTCTTGGCTAATG
TTCTTAGTGTTCTGTGTTGGCATCGGTTGTCTACCACTAGTCCAGACAGCCCAGAGAA(reverse)-3'

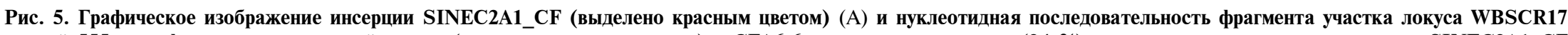

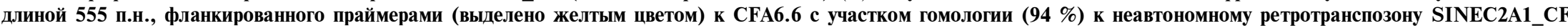
(выделено красным цветом) (Б). Гексануклеотид ААТААА (сигнал терминации транскрипции) выделен голубым.

A

$1 \oplus 0 \ominus$ •

Б

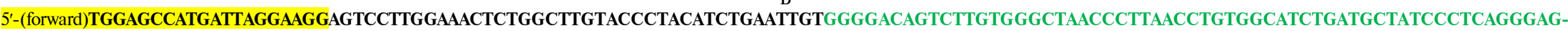

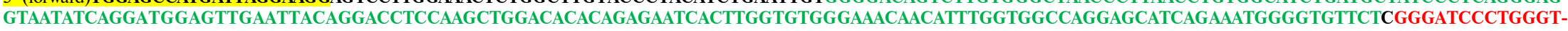

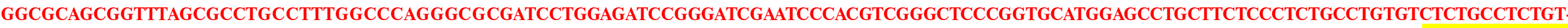

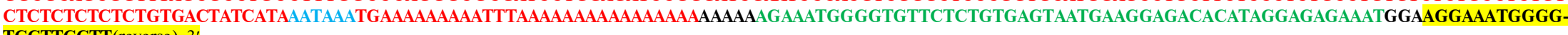
TCCTTCCTT(reverse)-3'

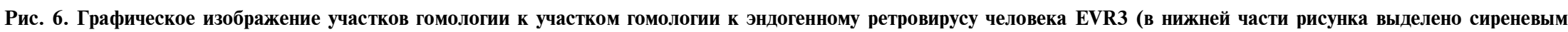

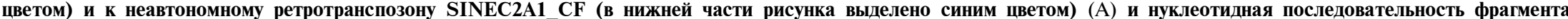

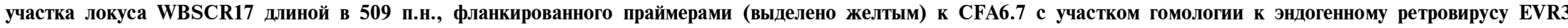

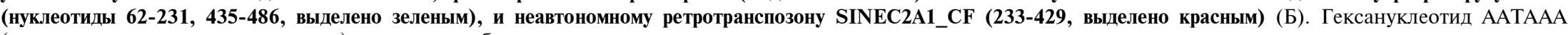
(сигнал терминации транскрипции) выделен голубым. 
Далее с использованием Giri Repbase и программного обеспечения CENSOR (28) в участках 6-й хромосомы Cfa6.6 и Cfa6.7 (см. рис. 3, 4) был выполнен поиск областей гомологии к различным транспозонам. Оказалось, что в Cfa6.6, полученных из разных источников (ROS_Cfam_1.0 и UNSW_CanFamBas_1.0), присутствует последовательность (183-370-й нуклеотид, табл. 1), на 94 \% гомологичная фрагменту неавтономного диспергированного ядерного элемента SINEC2A1_CF длиной в 188 п.н. - типичного представителя таких диспергированных повторов у собак.

На рисунке 5 представлены графическое изображение позиционирования этого транспозона (рис. 5, А) в выявленном фрагменте Сfa6.6 и его нуклеотидная последовательность (Б, выделено красным цветом).

1. Результат анализа присутствия/отсутствия диспергированных повторов в участке Cfa6.6 длиной 555 п.н., фланкированном праймерами (использованы Giri Repbase https://www.girinst.org/repbase/ и программное обеспечение CENSOR http://www.girinst.org/censor/index.php)

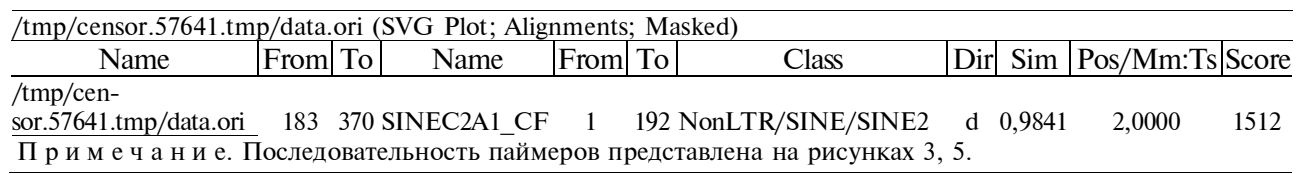

2. Результат анализа присутствия/отсутствия диспергированных повторов в участке Cfa6.7 длиной 509 п.н., фланкированном праймерами (использованы Giri Repbase https://www.girinst.org/repbase/ и программное обеспечение CENSOR http://www.girinst.org/censor/index.php)

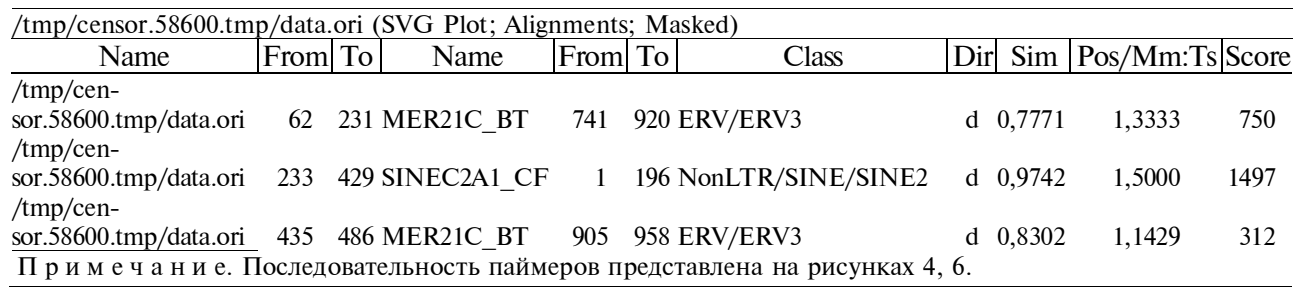

Фланкированный праймерами к CFA6.7 фрагмент локуса WBSCR17 длиной 504 п.н. несет участки гомологии к эндогенному ретровирусу EVR3 (нуклеотиды 62-231-й, 435-486-й) и к тому же самому неавтономному ретротранспозону SINEC2A1_CF (94 \% гомологии, нуклеотиды 233-429-й) длиной 197 п.н. (табл. 2, рис. 6).

Следует отметить, что в обоих фрагментах, гомологичных SINEC2A1_CF, присутствуют гексануклеотиды, соответствующие сигналу полиаденилирования - ААТААА, который служит ключевым регулятором окончания транскрипта. Этот гексамер или аналогичная последовательность очень часто обнаруживаются в пределах 30 п.н. от 3'UTR-концов (29). Ретротранспозоны класса SINE встречаются во всех геномах с высоким числом копий. Встроенные в гены, они могут нарушать экспрессию, изменять сплайсинг или останавливать транскрипцию. Геном домашней собаки несет сотни тысяч таких вставок, что способно существенно повлиять на транскрипцию генов, в ближайшем окружении или в интронах которых находятся такие инсерции (29). Из этого следует, что снижение экспрессии генов с инсерциями этих транспозонов может быть обусловлено не только индуцированным ими изменением рисунка метилирования, как предполагают некоторые исследователи (23), но и присутствием гексануклеотида ААТААА.

Данные, представленные в Repbase, свидетельствуют о том, что EVR3 имеет участки гомологии с мобильным генетическим элементом 
человека MER21C, а также с длинным концевым повтором одного из эндогенных ретровирусов крупного рогатого скота (30).

Из этого следует, что эндогенный ретровирус человека EVR3 непосредственно участвует в геномной нестабильности WBSCR17, и его внедрение в этот район ассоциировано с изменением транскрипции группы генов. Это может подтверждать не только идею о длительном и направленном отборе собак по признаку заинтересованности в контакте с человеком с самых ранних этапов доместикации, но и свидетельствовать о вовлечении ретровирусов в горизонтальный перенос у различных видов (в частности, у крупного рогатого скота), объединенных единой экологической нишей.

Полученные результаты позволяют сделать следующее заключение. Обязательное условие для доместикации - формирование специфической ниши, создаваемой человеком. Ключевым фактором при этом служит отбор биообъектов, в случае животных - особей с повышенной социальной активностью и способностью адаптироваться к условиям, модифицируемым человеком. Для обеспечения успешности такого отбора за относительно короткий период доместикации необходимо наличие повышенной генетической изменчивости, позволяющей отбирать желательные фенотипы (31). Одним из источников такой изменчивости могут быть мобильные генетические элементы.

Накопленные данные свидетельствуют о том, что геном домашней собаки, рассматриваемой в качестве модельного объекта доместикации, отличается от геномов близкородственных диких псовых определенной избыточностью ретротранспозонов (26), вносящих существенный вклад в генную и геномную изменчивость. Формирование новой ниши предполагает широкий обмен между биообъектами, в том числе экзогенными ретровирусами, прямыми или измененными потомками которых являются автономные ретротранспозоны, вовлекающие в эту изменчивость и неавтономные ретротранспозоны. Повышенная изменчивость районов с высокой плотностью факторов регуляции транскрипции генов, вовлеченных в высшую нервную деятельность (в частности, в социализацию) с прямым участием ретротранспозонов (см. рис. 5, 6), свидетельствует о том, что обобщение генетических ресурсов посредством переносов генетического материала исходных патогенов между видами может быть источником их генетических взаимосвязей и внутривидовой изменчивости при формировании общей ниши. Этим же может объясняться присутствие в ключевом геномном сегменте, изменчивость которого ассоциирована с гиперсоциализацией у собак, участков гомологии к эндогенному вирусу человека ERV3, выявленное в наших исследованиях.

Таким образом, мы показали, что собаки разного происхождения, а также такие межвидовые гибриды, как шалайки, действительно характеризуются полиморфизмом по длинам гена WBSCR17, то есть инсерциями транспозирующихся последовательностей, что ассоциировано с повышенной социализацией. Анализ таких инсерций в референтном геноме домашней собаки свидетельствует о том, что в них обнаруживаются неавтономный транспозон, встречающийся в геноме собак с высокой частотой, а также участок гомологии к ретротранспозону, впервые описанному у человека и имеющему гомологию с ретротранспозоном крупного рогатого скота. Можно ожидать, что именно общность вирома, объединяющая представителей одной ниши на уровне геномов, создает необходимую изменчивость, из которой отбираются особи с повышенной предрасположенностью к межвидовым взаимодействиям, что и лежит в основе формирования аграрной цивилизации. 
Авторы выражают искреннюю благодарность к.б.н. Ларисе Михайловне Федоровой за интерес, проявленный к работе, плодотворную дискуссию и полезные советы при подготовке статьи к опубликованию.

\section{ЛИТЕРАТУРА}

1. Zeder M.A. Core questions in domestication research. Proceedings of the National Academy of Sciences, 2015, 112(11): 3191-3198 (doi: 10.1073/pnas.1501711112).

2. Zeder M.A. Domestication as a model system for the extended evolutionary synthesis. Interface Focus, 2017, 7(5): 20160133 (doi: 10.1098/rsfs.2016.0133).

3. Colino-Rabanal V.J., Rodríguez-Díaz R., Blanco-Villegas M.J., Peris SJ, Lizana M. Human and ecological determinants of the spatial structure of local breed diversity. Sci Rep., 2018, 8(1): 6452 (doi: 10.1038/s41598-018-24641-3).

4. Sánchez-Villagra M.R., van Schaik C.P. Evaluating the self-domestication hypothesis of human evolution. Evolutionary Anthropology, 2019, 28(3): 133-143 (doi: 10.1002/evan.21777).

5. FAO. The Second Report on the State of the World's Animal Genetic Resources for Food and Agriculture /B.D. Scherf, D. Pilling (eds.). FAO Commission on Genetic Resources for Food and Agriculture Assessments, Rome, 2015. Режим доступа: http://www.fao.org/3/a-i4787e/index.html. Без даты.

6. Ostrander E.A., Wang G.D., Larson G., von Holdt B.M., Davis B.W., Jagannathan V., Hitte C., Wayne R.K., Zhang Y.P., Dog10K Consortium. Dog10K: an international sequencing effort to advance studies of canine domestication, phenotypes and health. National Science Review, 2019, 6(4): 810-824 (doi: 10.1093/nsr/nwz049).

7. Sykes N., Beirne P., Horowitz A., Jones I., Kalof L., Karlsson E., King T., Litwak H., McDonald R.A., Murphy L.J., Pemberton N., Promislow D., Rowan A., Stahl P.W., Tehrani J., Tourigny E., Wynne C.D.L., Strauss E., Larson G. Humanity's best friend: a dog-centric approach to addressing global challenges. Animals (Basel), 2020, 10(3): 502 (doi: 10.3390/ani10030502).

8. Zanella M., Vitriolo A., Andirko A., Martins P.T., Sturm S., O'Rourke T., Laugsch M., Malerba N., Skaros A., Trattaro S., Germain P.L., Mihailovic M., Merla G., Rada-Iglesias A., Boeckx C., Testa G. Dosage analysis of the 7q11.23 Williams region identifies BAZ1B as a major human gene patterning the modern human face and underlying self-domestication. Science Advances, 2019, 5(12): eaaw7908 (doi: 10.1126/sciadv.aaw7908).

9. Antonell A., Del Campo M., Magano L.F., Kaufmann L., de la Iglesia J.M., Gallastegui F., Flores R., Schweigmann U., Fauth C., Kotzot D., Pérez-Jurado L.A. Partial 7q11.23 deletions further implicate GTF2I and GTF2IRD1 as the main genes responsible for the Williams-Beuren syndrome neurocognitive profile. Journal of Medical Genetics, 2010, 47(5): 312-320 (doi: 10.1136/jmg.2009.071712).

10. Etokebe G.E., Axelsson S., Svaerd N.H., Storhaug K., Dembi Z. Detection of hemizygous chromosomal copy number variants in Williams-Beuren Syndrome (WBS) by duplex quantitative PCR array: an unusual type of WBS genetic defect. International Journal of Biomedical Science, 2008; 4(3): 161-170.

11. Ferrero G.B., Howald C., Micale L., Biamino E., Augello B., Fusco C., Turturo M.G., Forzano S., Reymond A., Merla G. An atypical 7q11.23 deletion in a normal IQ Williams-Beuren syndrome patient. Eur. J. Hum. Genet., 2010, 18(1): 33-38 (doi: 10.1038/ejhg.2009.108).

12. López-Tobón A., Trattaro S., Testa G. The sociability spectrum: evidence from reciprocal genetic copy number variations. Molecular Autism, 2020, 11(1): 50 (doi: 10.1186/s13229-020-00347-0).

13. Li H.H., Roy M., Kuscuoglu U., Spencer C.M., Halm B., Harrison K.C., Bayle J.H., Splendore A., Ding F., Meltzer L.A., Wright E., Paylor R., Deisseroth K., Francke U. Induced chromosome deletions cause hypersociability and other features of Williams-Beuren syndrome in mice. EMBO Mol. Med., 2009, 1(1): 50-65 (doi: 10.1002/emmm.200900003).

14. Makeyev A.V., Bayarsaihan D. Molecular basis of Williams-Beuren syndrome: TFII-I regulated targets involved in craniofacial development. The Cleft Palate-Craniofacial Journal, 2011, 48(1): 109-116 (doi: 10.1597/09-093).

15. Lopatina O.L., Komleva Y.K., Gorina Y.V., Olovyannikova R.Y., Trufanova L.V., Hashimoto T., Takahashi T., Kikuchi M., Minabe Y., Higashida H., Salmina A.B. Oxytocin and excitation/inhibition balance in social recognition. Neuropeptides, 2018, 72: 1-11 (doi: 10.1016/j.npep.2018.09.003).

16. Sohal V.S., Rubenstein J.L.R. Excitation-inhibition balance as a framework for investigating mechanisms in neuropsychiatric disorders. Mol. Psychiatry, 2019, 24(9): 1248-1257 (doi: 10.1038/s41380-019-0426-0).

17. von Holdt B.M., Shuldiner E., Koch I.J., Kartzinel R.Y., Hogan A., Brubaker L., Wanser S., Stahler D., Wynne C.D.L., Ostrander E.A., Sinsheimer J.S., Udell M.A.R. Structural variants in genes associated with human Williams-Beuren syndrome underlie stereotypical hypersociability in domestic dogs. Science Advances, 2017, 3(7): e1700398 (doi: 10.1126/sciadv.1700398).

18. Somel M., Franz H., Yan Z., Lorenc A., Guo S., Giger T., Kelso J., Nickel B., Dannemann M., Bahn S., Webster M.J., Weickert C.S., Lachmann M., Pääbo S., Khaitovich P. Transcriptional neoteny in the human brain. Proceedings of the National Academy of Sciences, 2009, 106(14): 5743- 
5748 (doi: 10.1073/pnas.0900544106).

19. Kukekova A.V., Johnson J.L., Xiang X., Feng S., Liu S., Rando H.M., Kharlamova A.V., Herbeck Y., Serdyukova N.A., Xiong Z., Beklemischeva V., Koepfli K.P., Gulevich R.G., Vladimirova A.V., Hekman J.P., Perelman P.L., Graphodatsky A.S., O’Brien S.J., Wang X., Clark A.G., Acland G.M., Trut L.N., Zhang G. Red fox genome assembly identifies genomic regions associated with tame and aggressive behaviours. Nat. Ecol. Evol., 2018, 2(9): 1479-1491 (doi: 10.1038/s41559-018-0611-6).

20. Nakamura N., Toba S., Hirai M., Morishita S., Mikami T., Konishi M., Itoh N., Kurosaka A. Cloning and expression of a brain-specific putative UDP-GalNAc: polypeptide N-acetylgalactosaminyltransferase gene. Biological and Pharmaceutical Bulletin, 2005, 28(3): 429-433 (doi: $10.1248 / \mathrm{bpb} .28 .429)$.

21. Nakayama Y., Nakamura N., Oki S., Wakabayashi M., Ishihama Y., Miyake A., Itoh N., Kurosaka A. A putative polypeptide $\mathrm{N}$-acetylgalactosaminyltransferase/Williams-Beuren syndrome chromosome region 17 (WBSCR17) regulates lamellipodium formation and macropinocytosis. Journal of Biological Chemistry, 2012, 287(38): 32222-32235 (doi: 10.1074/jbc. M112.370932).

22. Merla G., Ucla C., Guipponi M., Reymond A. Identification of additional transcripts in the Williams-Beuren syndrome critical region. Hum. Genet., 2002, 110(5): 429-438 (doi: 10.1007/s00439-002-0710-x).

23. Tandon D., Ressler K., Petticord D., Papa A., Jiranek J., Wilkinson R., Kartzinel R.Y., Ostrander E.A., Burney N., Borden C., Udell M.A.R., Von Holdt B.M. Homozygosity for mobile element insertions associated with WBSCR17 could predict success in assistance dog training programs. Genes (Basel), 2019, 10(6): 439 (doi: 10.3390/genes10060439).

24. Kajikawa M., Okada N. LINEs mobilize SINEs in the eel through a shared 3' sequence. Cell, 2002, 111: 433-444 (doi: 10.1016/S0092-8674(02)01041-3).

25. von Holdt B.M., Ji S.S., Aardema M.L., Stahler D.R., Udell M.A.R., Sinsheimer J.S. Activity of genes with functions in human Williams-Beuren syndrome is impacted by mobile element insertions in the gray wolf genome. Genome Biology and Evolution, 2018, 10(6): 1546-1553 (doi: 10.1093/gbe/evy112).

26. Wang G.D., Shao X.J., Bai B., Wang J., Wang X., Cao X., Liu Y.H., Wang X., Yin T.T., Zhang S.J., Lu Y., Wang Z., Wang L., Zhao W., Zhang B., Ruan J., Zhang Y.P. Structural variation during dog domestication: insights from grey wolf and dhole genomes. National Science Review, 2019, 6(1): 110-122 (doi: 10.1093/nsr/nwy076).

27. Sundman A.S., Pértille F., Lehmann Coutinho L., Jazin E., Guerrero-Bosagna C., Jensen P. DNA methylation in canine brains is related to domestication and dog-breed formation. PLoS ONE, 2020, 15(10): e0240787 (doi: 10.1371/journal.pone.0240787).

28. Kohany O., Gentles A.J., Hankus L., Jurka J. Annotation, submission and screening of repetitive elements in Repbase: Repbase Submitter and Censor. BMC Bioinformatics, 2006, 7: 474 (doi: 10.1186/1471-2105-7-474).

29. Choi J.D., Del Pinto L.A., Sutter N.B. SINE retrotransposons import polyadenylation signals to 3'UTRs in dog (Canis familiaris). bioRxiv preprint, 2020 (doi: 10.1101/2020.11.30.405357). December 1, 2020.

30. Jurka J. Long terminal repeats from domestic cow. Repbase Reports, 2008, 8(8): 847-847.

31. Glazko V., Zybailov B., Glazko T. Asking the Right question about the genetic basis of domestication: what is the source of genetic diversity of domesticated species? Advancements in Genetic Engineering, 2015, 4(2): 125 (doi: 10.4172/2169-0111.1000125).

\section{ІФГБОУ ВПО Российский государственный} аграрный университет-МСХА им. К.А. Тимирязева,

127550 Россия, г. Москва, ул. Тимирязевская, 49,

e-mail: vigvalery@gmail.com, aida-cat@yandex.ru, an.zhirkowa@yandex.ru, tglazko@rambler.ru $₫$;

2ФГБНУ НИИ пушного звероводства и кролиководства

им. В.А. Афанасьева,

140143 Россия, Московская обл., Раменский р-н, пос. Родники,

ул. Трудовая, 6 ,

e-mail: gkosovsky@mail.ru
Поступила в редакцию 2 декабря 2020 года

Sel'skokhozyaistvennaya biologiya [Agricultural Biology], 2021, V. 56, № 2, pp. 292-303

\title{
SOCIALIZATION AND GENETIC VARIABILITY AS A DRIVER OF DOMESTICATION (BY THE EXAMPLE OF DOG BREEDS)
}

\author{
V.I. Glazko1, 2, G.Yu. Kosovsky², T.V. Blokhina', A.A. Zhirkova', T.T. Glazko', $2 \bowtie$
}


${ }^{1}$ Timiryazev Russian State Agrarian University-Moscow Agrarian Academy, 49, ul. Timiryazevskaya, Moscow, 127550 Russia, e-mail vigvalery@gmail.com, aida-cat@yandex.ru, an.zhirkowa@yandex.ru, tglazko@rambler.ru ( $₫$ corresponding author);

${ }^{2}$ Afanas'ev Research Institute of Fur-Bearing Animal Breeding and Rabbit Breeding, 6, ul. Trudovaya, pos. Rodniki, Ramenskii Region, Moscow Province, 140143 Russia, e-mail gkosovsky@mail.ru

ORCID:

Glazko V.I. orcid.org/0000-0002-8566-8717

Kosovskii G.Yu. orcid.org/0000-0003-3808-3086

Blokhina T.V. orcid.org/0000-0002-1126-2781

Zhirkova A.A. orcid.org/0000-0001-5985-9395

The authors declare no conflict of interests

Acknowledgements:

The authors are sincerely grateful to Larissa M. Fedorova $\mathrm{PhD}$ for her interest in the problem of domestication, fruitful discussion and helpful advice in preparing this article for publication.

Received December 2, 2020

doi: 10.15389/agrobiology.2021.2.292eng

\begin{abstract}
Social activity is the basis of interaction between different species in the process of common niche forming, including animal domestication. The increased social activity is universal characteristic of the "domestication syndrome" for different species (M.A. Zeder, 2017). It is assumed that some elements of this increase are due to a certain neotenization of a number of brain metabolic pathways (M. Somel et al., 2009). This is in good agreement with the data on the association of "domestication syndrome" with the slowing of neural crest cell proliferation (M.A. Zeder, 2015). The syndrome of hypersocialization (Williams-Behren Syndrome - WBS) in humans has been described, associated with hemideletion/hemiduplication of the 7q11.23 region, which includes $25-28$ genes whose products are critical for the activity of various aspects of the central nervous system (A. Antonell et al., 2010). It was found that the complex of such genes is located on chromosome 6 in canids, and the domestic dog, considered in recent years as the main model object for studying the genetic mechanisms of domestication (E.A. Ostrander et al., 2019), differs from wolves in the presence of transposon insertions, increased methylation, and reduced gene expression in this region (B.M. von Holdt et al., 2017, 2018; D. Tandon et al., 2019). The aim of this work was to analyze such insertions in the region of the key gene for increased social activity in dogs WBSCR17 (Cfa6.6 and Cfa6.7) in representatives of different breeds and interspecific hybrids with jackals, as well as finding out the presence of mobile genetic elements in these areas. The detected sequences have high homology to the non-autonomous dispersed nuclear element SINEC2A1_CF (94\% homology) and to two regions of endogenous retrovirus 3 the sequences of which are described in humans and cattle (approximately $80 \%$ homology). Data were obtained on the increased variability of the presence and number of insertions into these areas in dogs of different breeds and hybrids, on the presence of homology sites to endogenous human and bovine retroviruses, as well as a short dispersed nuclear element, species-specific for domestic dogs, SINEC2A1_CF, carrying the hexanucleotide AATAAA which contributes to the completion of transcription. These finding suggest the involvement of retroviruses in the formation of an aggregate niche in the domestication process, which leads to increased variability that contributes to the selection of animals with hypersocialization.
\end{abstract}

Keywords: domestication, hypersocialization, Williams-Behren syndrome, retrotransposons, dog breeds and hybrids, aggregate niche. 